\title{
Effect of T-2 Toxin on Regional Blood Flow and Vascular Resistance in the Conscious Rat
}

\author{
ANNA-LeEna Sirén and Giora Feuerstein \\ Department of Neurology. Neurobiology Research Division. Uniformed Services University of the Health Sciences, \\ 4301 Jones Bridge Road, Bethesda. Maryland 20814
}

Received July 26, 1985; accepted December 2. 1985

\begin{abstract}
Effect of T-2 Toxin on Regional Blood Flow and Vascular Resistance in the Conscious Rat. SirÉn, A.-L., AND Feuerstein, G. (1986). Toxicol. Appl. Pharmacol. 83, 438-444. The acute effect of T-2 toxemia on local blood flow and vascular resistance in hindquarter, mesenteric, and renal vascular beds was continuously measured by the directional pulsed Doppler technique in conscious, male Sprague-Dawley rats. Intravenous injection of T-2 toxin $(1 \mathrm{mg} / \mathrm{kg})$ in the conscious rat reduced blood flow and increased vascular resistance in all blood vessels studied but had no significant effect on mean arterial pressure or heart rate. The blood flow in hindquarters gradually decreased to a minimum of $-77 \pm 9 \%$ (mean \pm SE) $6 \mathrm{hr}$ after the toxin injection. The hindquarter vascular resistance concomitantly increased to a maximum value of $+323 \pm 69 \%$ above the resistance before toxin administration. Mesenteric and renal blood flow initially increased (slightly) and then gradually decreased. The maximum drop of blood flow, $-90 \pm 13 \%$ and $-76 \pm 13 \%$ for the mesenteric and renal vascular beds, respectively, was achieved $4 \mathrm{hr}$ after T-2 toxin injection and the blood flow values remained low for up to $6 \mathrm{hr}$. Simultaneously with the impairment of blood flow the mesenteric and renal vascular resistance increased to reach the maximal values of $+404 \pm 99 \%$ and $+556 \pm 15 \%$, respectively. In addition, plasma renin activity was markedly elevated $(+653 \pm 160 \%)$ at the time of reduced renal blood flow. Intravenous injection of the same value of vehicle ( $10 \%$ ethanol in saline) had no significant effect on any of the cardiovascular variables studied. Two of five rats in the T-2 toxin-treated group died within $5 \mathrm{hr}$ after the T-2 toxin injection and only one animal survived $24 \mathrm{hr}$ while all the control animals survived over $24 \mathrm{hr}$. The results suggest that strong vasoconstriction in skeletal muscle, mesenteric, and renal vascular beds leads to impairment of local blood flow. The ischemia in vital organs together with the earlier reported decrease in cardiac output by T-2 toxin might then be the cause of rapid death in acute T-2 toxemia. (c) 1986 Academic Press. Inc.
\end{abstract}

$\mathrm{T}-2$ toxin is a trichothecene mycotoxin which as a natural contaminant of foods and animal feeds may cause severe illness in animals and man (for review see Ueno, 1985). In humans chronic exposure to $\mathrm{T}-2$ toxin produces a fatal disorder characterized by fever, vomiting. leukopenia, hemorrhage, and bone marrow depression (Ueno, 1985). Acute parenteral administration of $\mathrm{T}-2$ toxin to rats, guinea pigs, and other experimental animals induces shock, hypothermia, and death due to cardiovascular and respiratory failure (Sato $e t$ al. 1975; Weaver et al.. 1978: Feuerstein et al.,
1985). In anesthetized rats, intravenous infusion of T-2 toxin causes a triphasic circulatory response: initial decrease in heart rate and blood pressure followed by tachycardia and hypertension and finally bradycardia and hypotension (Smalley et al., 1968; Wilson et al. 1982). It was recently shown in our laboratory that systemically administered T-2 toxin induced strong rises of total peripheral resistance in the conscious rat, while the cardiac output gradually decreased leading to cardiovascular collapse and death (Feuerstein et al., 1985). Concomitantly with the increases in mean ar- 
terial pressure and total peripheral resistance, $\mathrm{T}-2$ toxin injection also induced rises in the plasma catecholamine levels and resulted in metabolic acidosis in conscious rats (Feuerstein et al.. 1985). Recently, T-2 toxin has been shown to produce vasoconstriction in an in vitro bovine ear perfusion system (Wilson and Gentry, 1985), but its effect on local blood flow in intact animals has not been reported. Since calculating total peripheral resistance does not reveal which vascular beds are constricted, we decided to study the effect of T-2 toxin on regional blood flow and vascular resistance in some distinct vascular beds (muscle, mesenteric, renal) in the conscious rat.

\section{METHODS}

Male Sprague-Dawley rats (300-340 g) from Taconic Farms (Germantown, N.Y.) were used in all experiments. After surgical operations the rats were housed individually in plastic cages $(21 \times 27 \times 16 \mathrm{~cm} . \mathrm{W} \times \mathrm{L} \times \mathrm{H})$ with feed and water offered ad libitum.

Regional blood flow measurement with the pulsed Doppler lechnique. Rats (300-340 g) were anesthetized with a solution of ketamine $(100 \mathrm{mg} / \mathrm{ml})$ and acepromazine (1 $\mathrm{mg} / \mathrm{ml}$ ) administered intramuscularly in combination in a volume of $0.13 \mathrm{ml} / 100 \mathrm{~g}$ body wt. Miniaturized Doppler flow probes (Valpey-Fisher) were implanted around the abdominal aorta, superior mesenteric artery, and the left renal artery according to the method described earlier by Haywood et al. (1981). Briefly, a ventral midline laparotomy incision was made and 4-mm lengths of the lower abdominal aorta. the superior mesenteric artery, and the left renal artery were carefully isolated with the aid of a dissecting microscope. Miniature Doppler flow probes were then sutured around each vessel. The wire leads were tunneled beneath the skin and exteriorized at the nape of the neck where they were soldered to a connector plug which was fixed to the animal's skull with small screws and dental acrylic. Polyethylene catheters (PE50, Becton-Dickinson. Parsippany, N.J.) were implanted in the left femoral artery and vein for measurements of blood pressure and heart rate and for intravenous drug injections. The catheters were led beneath the back skin to exit at the nape of the neck and were then secured by a soft spring wire attached by an adhesive collar from the back of the neck and outside the cage. The animals were allowed to recover 2 to 3 days after the surgery.

On the day of the experiment the rat was connected to the flow-probe connectors and the connector line was suspended from the top of the animal's home cage to allow freedom of movement during the experiment. Regional blood flow was measured with a pulsed Doppler flowmeter (University of lowa Bioengineering Facility, Model 545c3). The arterial line was attached to a pressure transducer (Narco RPI 500i) and the blood pressure (systolic, diastolic, mean), heart rate. and regional blood flows were continuously recorded on the computerized Narcotrace $80 \mathrm{dy}$ nograph. Vascular resistance was calculated as the mean arterial pressure $(\mathrm{mm} \mathbf{H g}$ )/blood velocity (Doppler shift in kilohertz). Changes in blood flow and vascular resistance are expressed as a percentage of control values. T-2 toxin (Sigma Chemical Co., St. Louis, Mo.) was dissolved in dehydrated ethanol (U.S. Industrial Chemicals. New York, N.Y.) and further diluted with $0.9 \%$ (W/V) saline (sterile, pyrogen free) for a solution of $1 \mathrm{mg} / \mathrm{ml}$ of $\mathrm{T}-2$ toxin in $10 \%$ ethanol. A single bolus injection of $\mathrm{T}-2$ toxin $(1 \mathrm{mg} /$ $\mathrm{kg}$ ) was injected iv and continuous recordings were made for $6 \mathrm{hr}$ after the injection. The control animals received an iv injection of the same volume $(0.1 \mathrm{ml} / 100 \mathrm{~g}$ body wt) of vehicle ( $10 \%$ ethanol in saline) in each case.

Assay of plasma renin activity. The rats were anesthetized with $2 \%$ halothane in oxygen and femoral arterial lines were implanted $24 \mathrm{hr}$ before the experiment. Blood samples were taken before and 1, 4, and $6 \mathrm{hr}$ after the injection of T-2 toxin $(0.75 \mathrm{mg} / \mathrm{kg})$ or the corresponding volume $(0.1 \mathrm{ml} / 100 \mathrm{~g}$ body $\mathrm{wt})$ of vehicle ( $10 \%$ ethanol in saline) into the arterial line. Plasma renin was collected by dripping $300 \mu \mathrm{l}$ of blood from the arterial line directly into ice-cold vials containing $50 \mu \mathrm{l}$ of $10 \%$ EDTA. The samples were then immediately centrifuged and the plasma frozen in dry ice. The plasma samples were sent on dry ice to Dr. K. B. Brosnihan (Cleveland Clinic, Cleveland, Ohio) for analysis. The plasma renin activity (PRA) was assayed as previously described by Sen and co-workers (1969). The generated angiotensin I was measured by radioimmunoassay (RIA for Angiotensin I, New England Nuclear, Boston, Mass.).

Statistical analysis of data. Data in text and figures are expressed as mean $\pm S E$ for the indicated number of animals. Analysis of variance with repeated measures was used for the statistical evaluation of the data.

\section{RESULTS}

\section{Effect on Blood Flon' and Vascular Resistance}

Hindquarter blood flow and vascular resistance (Figures 1, 2). Intravenous injection of $\mathrm{T}-2$ toxin at the dose of $1 \mathrm{mg} / \mathrm{kg}$ induced a gradual reduction of hindquarter blood flow and raised hindquarter vascular resistance in the conscious rat. The maximum decline in blood flow $(-77 \pm 9 \%$, mean $\pm S E)$ and $\max -$ imum increase in vascular resistance $(+323$ $\pm 69 \%$ ) were reached about $6 \mathrm{hr}$ after the toxin 

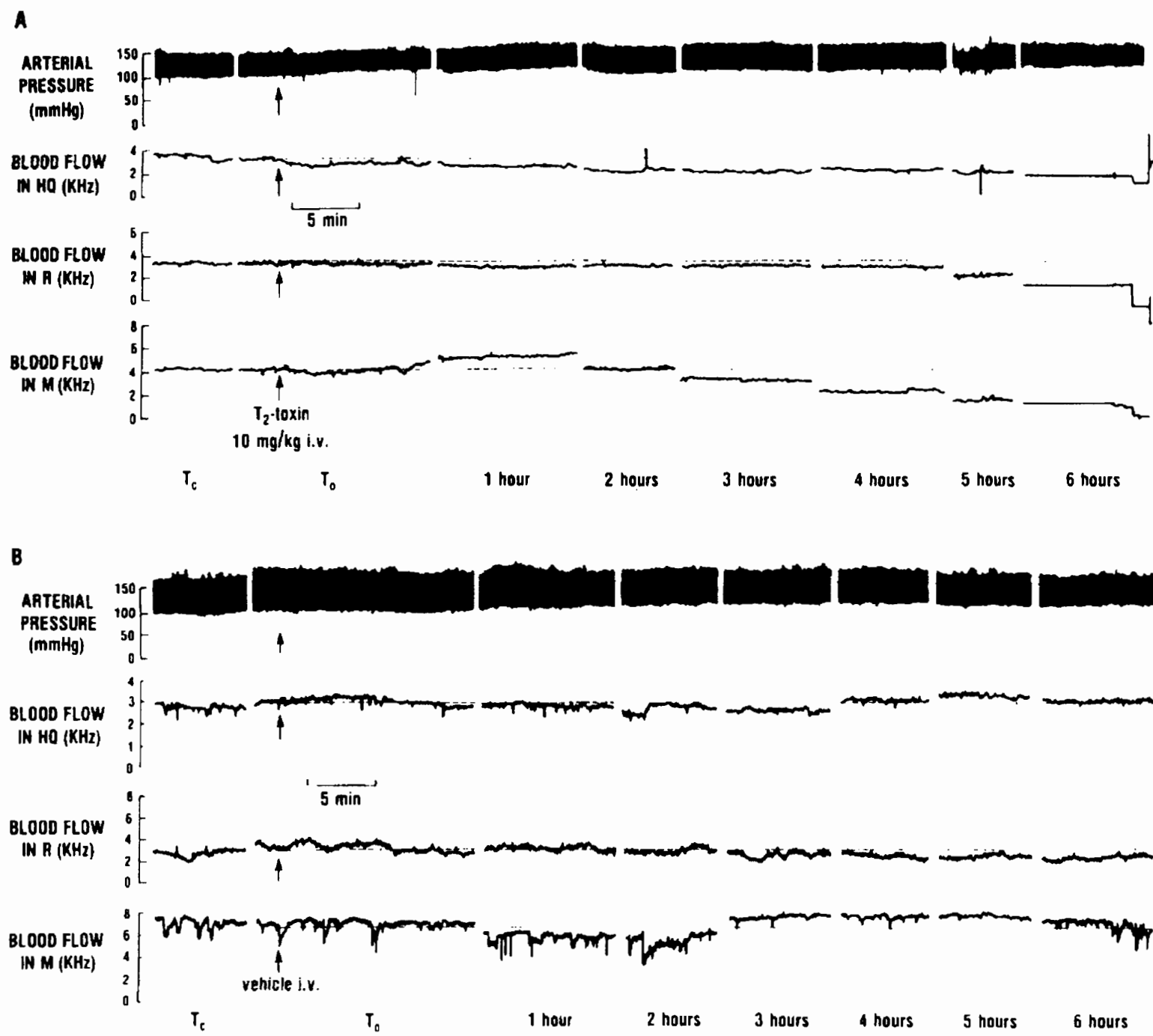

FIG. 1. Typical responses in the conscious rat of arterial pressure and mean blood flow velocity in hindquarter $(H Q)$, renal (R), and mesenteric (M) vascular beds to an intravenous bolus injection of T-2 toxin or vehicle. A single bolus injection of a $1-\mathrm{mg} / \mathrm{kg}$ dose of $\mathrm{T}-2$ toxin $(A)$ or the same volume of vehicle (10\% ethanol in saline, (B)) was injected at the $T_{n}$. $T_{\mathrm{c}}$ represents control period 20-30 min before $\mathrm{T}-2$ toxin or vehicle injection. Blood flow was measured with pulsed Doppler flowmeter. Dashed line denotes the blood flow level before injection.

administration. Intravenous injection of vehicle had no effect on hindquarter blood flow or vascular resistance.

Mesenteric and renal blood flow and vascular resistance (Figs. 1, 3, 4). Blood flow in mesenteric and renal arteries initially increased slightly but then gradually decreased after $\mathrm{T}$ 2 toxin injection ( $1 \mathrm{mg} / \mathrm{kg}$, iv) in the conscious rat. The maximum change in mesenteric blood flow $(-90 \pm 13 \%)$ was achieved about $4 \mathrm{hr}$ after the T-2 toxin administration and the blood flow remained impaired during the total observation period of $6 \mathrm{hr}$. The maximum reduction in renal blood flow $(-76$ $\pm 13 \%$ ) was also reached in 3 to $4 \mathrm{hr}$ and remained at this low level $6 \mathrm{hr}$ after the toxin administration.

Concomitant with the decrease in mesenteric and renal blood flow vascular resistance gradually increased in these blood vessels after $\mathrm{T}-2$ injection. The maximum rises of resistance, $+404 \pm 199 \%$ in the mesenteric and $+556 \pm 15 \%$ in the renal artery, were reached within $4 \mathrm{hr}$ after the toxin administration and 


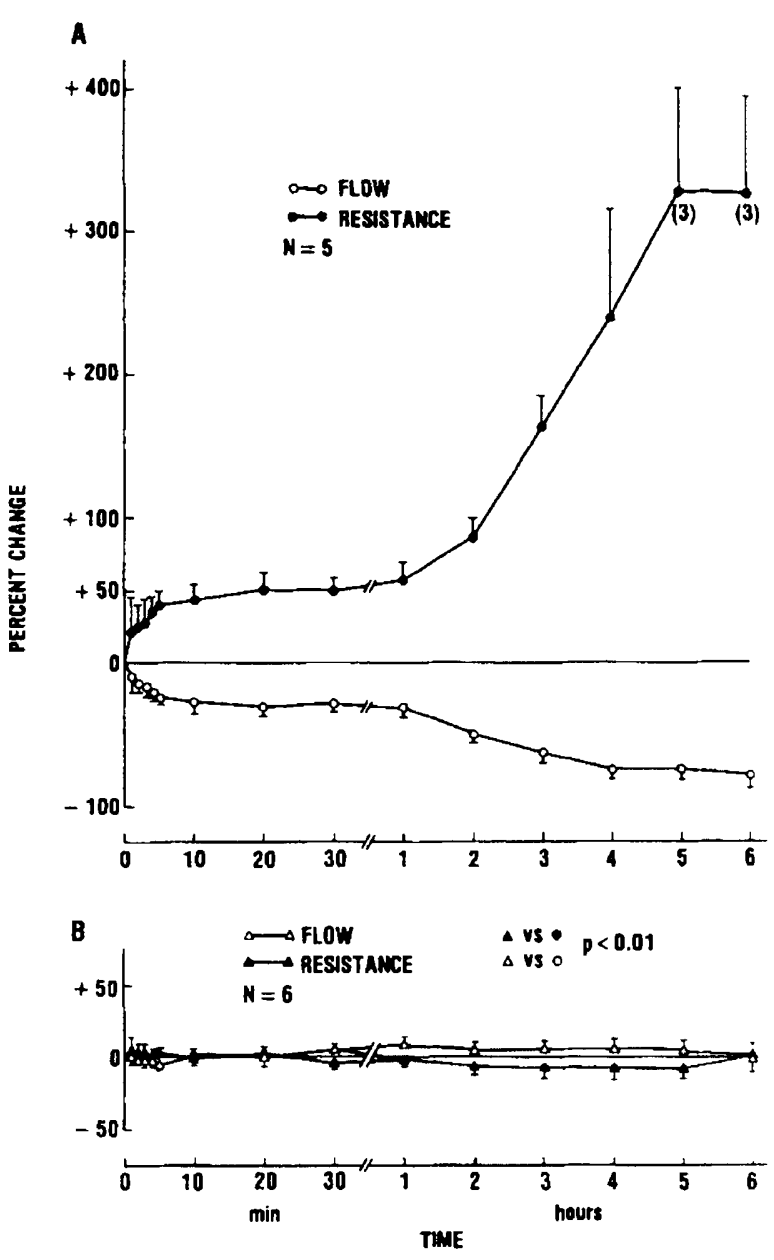

FiG. 2. Effect of T-2 toxin on hindquarter blood flow and vascular resistance in the conscious rat. A single bolus injection of a $1-\mathrm{mg} / \mathrm{kg}$ dose of T-2 toxin (A) or vehicle (B) was injected intravenously. Zero point denotes the control period immediately before injection. The statistical difference between T-2 toxin-treated and control groups was evaluated by analysis of variance with repeated measures and $p$ values for the two variables are given in the figure.

remained increased during the total observation period of $6 \mathrm{hr}$. Intravenous injection of vehicle had no significant effect on renal or mesenteric blood flow and vascular resistance.

Effect on Blood Pressure and Heart Rate (Fig. 5)

Systemic injections of $\mathrm{T}-2$ toxin $(1 \mathrm{mg} / \mathrm{kg}$, iv) or vehicle to conscious rats had no significant effect on mean arterial pressure and heart rate.
Survival after T-2 Toxin

Two rats out of five died within $5 \mathrm{hr}$ after the T-2 toxin injection ( $1 \mathrm{mg} / \mathrm{kg}$, iv), and only one out of five animals survived $24 \mathrm{hr}$, while all the control rats $(n=6)$ survived over $24 \mathrm{hr}$.
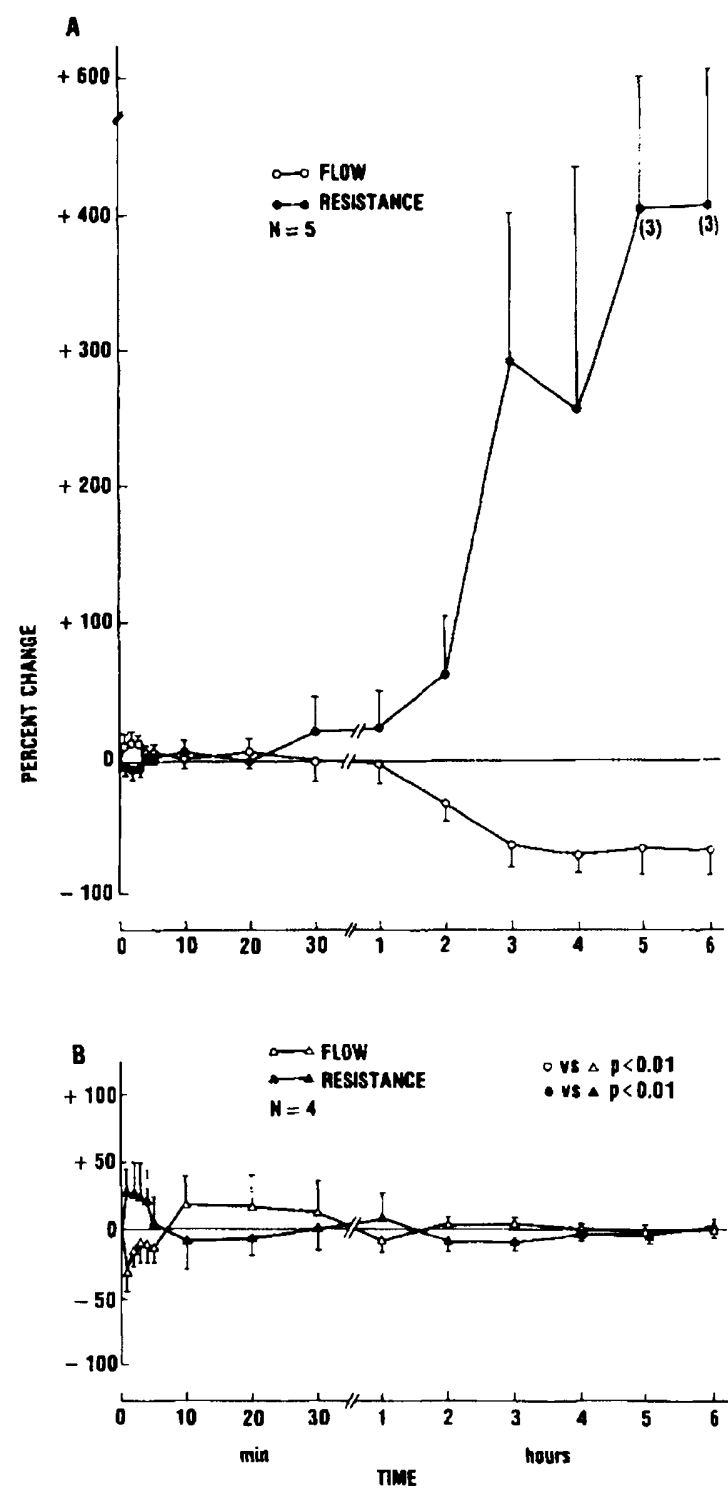

FIG. 3. Effect of $T-2$ toxin on mesenteric blood flow and vascular resistance in the conscious rat. $A$ single bolus injection of a $1-\mathrm{mg} / \mathrm{kg}$ dose of T-2 toxin (A) or vehicle (B) was injected intravenously. Zero point denotes the control period immediately before injection. The statistical difference between T-2 toxin-treated and control groups was evaluated by analysis of variance with repeated measures and $p$ values for the two variables are given in the figure. 


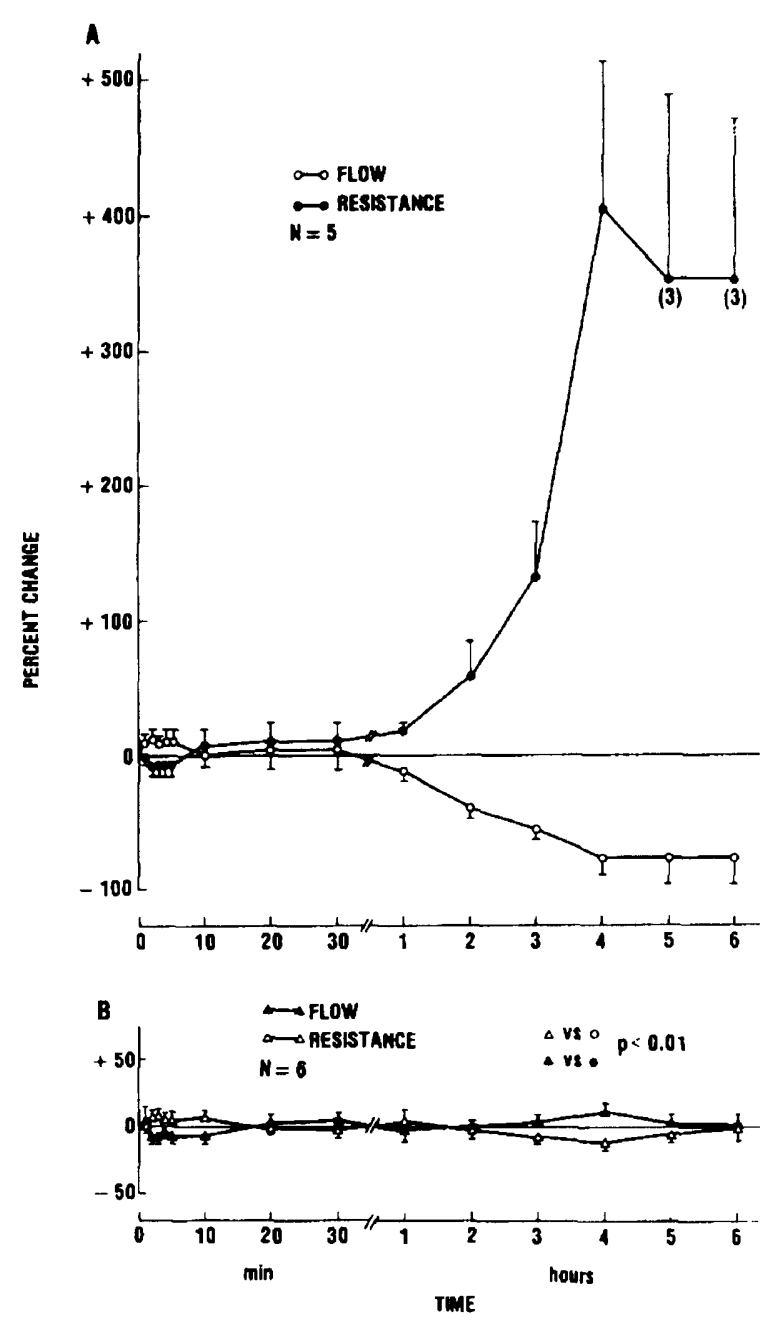

Fig. 4. Effect of T-2 toxin on renal blood flow and vascular resistance in the conscious rat. A single bolus injection of a $1-\mathrm{mg} / \mathrm{kg}$ dose of $\mathrm{T}-2$ toxin (A) or vehicle (B) was injected intravenously. Zero point denotes the control period immediately before injection. The statistical difference between T-2 toxin-treated and control groups was evaluated by analysis of variance with repeated measures and $p$ values for the two variables are given in the figure.

\section{Effect on Plasma Renin Activity (Fig. 6)}

T-2 toxin $(0.75 \mathrm{mg} / \mathrm{kg}$, ia) induced a significant increase in plasma renin activity 4 and $6 \mathrm{hr}$ after the toxin administration, while the vehicle had no effect on PRA levels.

\section{DISCUSSION}

Previous studies have shown that the trichothecene mycotoxin, T-2 toxin, produces complex cardiovascular effects depending on the animal species used, route of administration, degree of purity of the toxin, and state of consciousness of the animal (Ueno et al.. 1971). In the conscious rat acute systemic administration of T-2 toxin results in a dose-dependent increase in mean arterial pressure and heart rate followed by hypotension (Feuerstein et al., 1985). Furthermore, concomitant with the rises of mean arterial pressure and heart rate, $T-2$ toxin $(1 \mathrm{mg} / \mathrm{kg}$, ia) increases the total peripheral resistance and decreases the cardiac output in awake rats (Feuerstein et al., 1985). Severe decrease in cardiac output was also reported after intravenous injection of T-2 toxin $(0.6-4.8 \mathrm{mg} / \mathrm{kg}$ ) in swine (Lorenzana et al., 1984), and the reduction in cardiac performance was suggested to be the major cause of cardiovascular collapse and death in acute T-2 toxemia (Feuerstein et al., 1985; Lorenzana et al., 1984). In the present study we failed to demonstrate any significant effect for a 1 $\mathrm{mg} / \mathrm{kg}$ dose of $\mathrm{T}-2$ toxin on blood pressure or heart rate. Despite this lack of effect of the

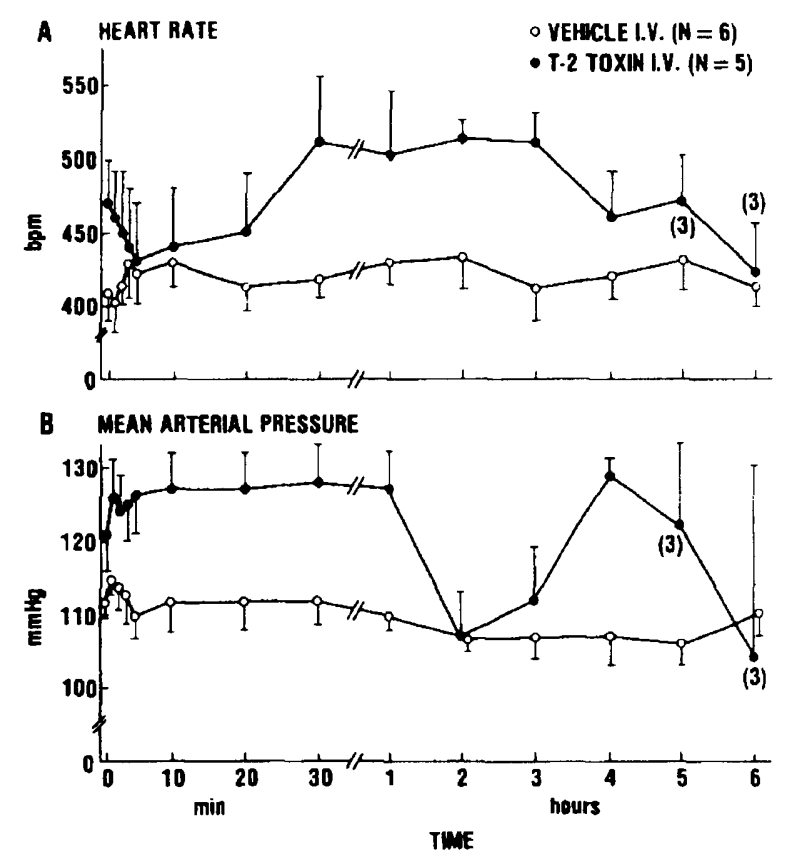

FIG. 5. Effect of T-2 toxin on mean arterial pressure and heart rate in the conscious rat. A single bolus injection of a $1-\mathrm{mg} / \mathrm{kg}$ dose of $\mathrm{T}-2$ toxin or vehicle was injected intravenously. Zero point denotes the control period immediately before injection. 


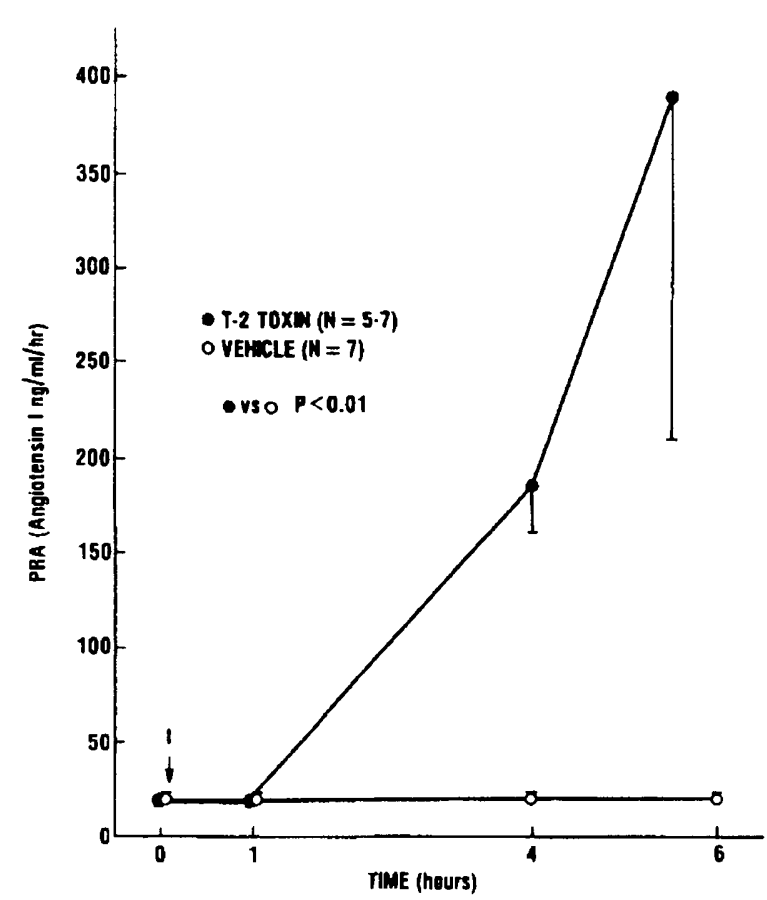

FIG. 6. Effect of $T-2$ toxin on plasma renin activity (PRA) in the conscious rat. The same volume of T-2 toxin $(0.75 \mathrm{mg} / \mathrm{kg})$ or vehicle was injected into the arterial line $T_{0} .1$ denotes the injection. The statistical difference between T-2 toxin-treated and control groups was evaluated by analysis of variance with repeated measures and $p$ value for the change in plasma renin activity is given in the figure.

toxin on gross cardiovascular variables. T-2 toxin caused marked impairment of blood flow and increased the vascular resistance in hindlimb skeletal muscles, mesenteric, and renal vascular beds. Thus, these results further clarify the mechanism of the detrimental action of T-2 toxin after acute parenteral administration: impaired blood flow in vital organs due to the reduction in cardiac output and the peripheral vasoconstriction.

The increase in vascular resistance induced by $\mathrm{T}-2$ toxin became apparent $1 \mathrm{hr}$ after the toxin administration and reached its maximum in 4 to $6 \mathrm{hr}$. Recent studies in our laboratory revealed the same time course for the increase in total peripheral resistance elicited by the same dose of $\mathrm{T}-2$ toxin $(1 \mathrm{mg} / \mathrm{kg})$ in conscious rats (Feuerstein et al.. 1985). The marked vasoconstriction in muscle, mesenteric, and renal vasculature is likely to underlie the rise of total peripheral resistance produced by $\mathrm{T}-2$ toxin as previously reported (Feuerstein et al., 1985). In addition to its powerful action on hemodynamic variables, the systemic injection of T-2 toxin has been reported to increase plasma levels of catecholamines in the conscious rat, guinea pig, and swine (Feuerstein et al., 1985; Lorenzana et al., 1984). This suggests that the decreases in blood flow and increases in local vascular resistance induced by $\mathrm{T}-2$ toxin might be mediated by the activation of the sympathetic nervous system. Furthermore, in an in vitro bovine ear preparation $\mathrm{T}-2$ toxin has been reported to produce dose-dependent vasoconstriction which was not influenced by blockade of histaminic, adrenergic, or muscarinic receptors (Wilson and Gentry, 1985). This might further indicate that a direct action on the vascular smooth muscle contributes to the increase in vascular resistance in vivo.

In addition to its powerful action on renal blood flow, systemic injection of T-2 toxin increased the plasma renin activity. The increment of PRA became apparent $4 \mathrm{hr}$ after the toxin administration. Since at this time point also the renal blood flow was low, the increase in plasma renin activity by $\mathrm{T}-2$ toxin is likely due to its vasoconstriction action on renal blood flow.

In summary, the present study demonstrates that the systemic injection of $\mathrm{T}-2$ toxin produces marked reduction of local blood flow in muscle, mesenteric, and renal vascular beds leading to a concomitant increase in vascular resistance in these vascular beds. The previously reported reduction in cardiac output and generalized vasoconstriction due to a direct action on the vascular smooth muscle and/or strong activation of the sympathetic outflow by $T-2$ toxin may account for the impairment of blood flow. Furthermore, the striking rise of vascular resistance in muscle, mesenteric. and renal vasculature could be responsible for the earlier findings that systemic injection of $\mathrm{T}-2$ toxin caused an increase in total peripheral resistance in conscious rats. Ischemia in vital organs such as the kidneys together with the cardiodepressant action of $\mathrm{T}-2$ toxin may explain the rapid mortality in acute $\mathrm{T}-2$ toxemia. 


\section{ACKNOWLEDGMENTS}

This work was supported in part by USAMRIID Contract G19213. The opinions or assertions contained herein are the private ones of the authors and are not to be construed as official or reflecting the view of the Department of Defense or the Uniformed Services University of the Health Sciences. The experiments reported herein were conducted according to the principles set forth in the "Guide for the Care and Use of Laboratory Animals," Institute of Laboratory Animal Resources, National Research Council (DHEW Publication No. NIH 78-23, 1978). The authors wish to thank Dr. K. B. Brosnihan for the assays of plasma-renin activity. Ms. Wanda Patterson and Mrs. Muriel Christin are acknowledged for their help in preparing this manuscript.

\section{REFERENCES}

Feuerstein, G., Goldstein. D. S., Ramwell. P. W., ZERBE, R. L., LUX, W. E. JR., FADEN A. 1., AND BAYORH, M. A. (1985). Cardiorespiratory, sympathetic and biochemical responses to T-2 toxin in the guinea pig and rat. J. Pharmacol. Exp. Ther. 232, 786-794.

Haywood, J. R., Shaffer, R. A., Fastenow, C., Fink, C. D., AND BRODY. M. J. (1981). Regional blood flow measurement with pulsed Doppler flowmeter in conscious rat. Amer. J. Physiol. 241, H273-H278.

LoRenzana, P. I., Beasley, V. R., AND Buck, W. B. (1984). Changes in hemodynamics, catecholamines, 6 -
keto-PGF $F_{1 \alpha}$, thromboxane $B_{2}$ and serum ions during T-2 toxin induced shock. Fed. Proc. 43, 657.

Sato, N., Ueno. Y., AND ENomoto, M. (1975). Toxicological approaches to the toxic metabolites of Fusaria VII. Acute and subacute toxicities of T-2 toxin in cats. Japan. .J. Pharmacol. 25, 263-270.

Sen, S.. Smeby, R. R., and Bumpus, M. M. (1969). Plasma renin activity in hypertensive rats after treatment with renin inhibitor. Amer. J. Physiol. 216, 449-453.

Smalley, E. B., Marasas, W. F. O., Strong, F. M., BAMBURG. J. R., NICHOLS, R. E.. AND KOSURI, N. R. (1968). Mycotoxicosis associated with moldy corn. In Proceedings of the First U.S. Japan Conference on Toxic Microorganisms (M. Herzberg, ed.), pp. 163-173. UJNR Joint Panels on Toxic Microorganisms and the U.S. Department of the Interior, Washington, D.C.

UENO, Y. (1985). The toxicology of mycotoxins. ('RC' (rit. Rev. Tuxicol. 14, 99-132.

UENO, Y.. ISHIKaWA, Y., NAKAJIMA, M., SAKal, K.. ISHII, K.. TSUnoda. H., SatTo, M., EnOMOto, M., Ohtsubo, K., AND UMEDA, M. (1971). Toxicological approaches to the metabolites of Fusarium I. Screening of toxic strains. Japan. J. Exp. Med. 41, 257-263.

Weaver, G. A., Kurtz, H. J., AND Bates, F. Y. (1978). Acute and chronic toxicity of T-2 mycotoxin in swine. l'et. Rec. 103, 531-535.

Wilson, C. A.. Everard, D. M., and Schoental, R. (1982). Blood pressure changes and cardiovascular lesions found in rats given T-2 toxin, a trichothecene secondary metabolite of certain Fusarium microfungi. Toxicol. Lefl. 10, 35-40.

Wilson, D. J., AND GENTRY, P. A. (1985). T-2 toxin can cause vasoconstriction in an in vitro bovine ear perfusion system. Toxicol. Appl. Pharmacol. 79, 159-165. 